\title{
Exploring Low E-Participation in Policy Making in Ghana: A Case Study of Kumasi Metropolitan Assembly
}

\author{
Lois Tweneboa Kodua $^{1 *} \quad$ Bright Okyere Ofosu ${ }^{2}$ \\ School of Public Affairs and Administration, University of Electronic Science and Technology of China \\ Qingshuihe Campus: No. 2006 Xiyuan Ave,West Hi- Tech Zone, 611731
}

\begin{abstract}
The way people interact and collaborate with others in this modern society in terms of business and governance has seen drastic modification. Previously, demographic difference and distances of geographic locations always distance and separated citizen from the government. Fortunately, the emergence of Information Communication Technology (ICT) which has provided online platforms have helped bridged this gap. This study employed explanatory research design coupled with cross sectional and convenient sampling techniques to select a sample size of 219 respondents for the study. Primary and secondary data were used for the research. The study also employed the ordinary least squares multiple regression econometric model in estimating the impact of factors that influence E-participation in policy making of local government in Ghana Finally, the study concluded that trust factors have a negative influence on electronic participation in policy making of local government in Ghana and is not statistically significant whereas social factors such as culture and gender inequalities have a positive impact E-participation in policy making of local government in Ghana. Technical factors consisting of technological infrastructure and information technology literacy also has a positive impact on E-participation in policy making of local government in Ghana.
\end{abstract}

Keywords: Electronic Participation (E-Participation), Policy Making, Local Government, Kumasi Metropolitan Assembly

DOI: $10.7176 /$ RHSS/10-2-01

Publication date: January $31^{\text {st }} 2020$

\section{Introduction}

Over the past decade globally, Information Communication Technology (ICT) has affected the lives of humans in all aspects and it is not surprising that it is now an area that most research is geared towards. The way people interact and collaborate with others in this modern society in terms of business and governance has seen a drastic modification. The field of governance and public sector administration has not been left out of this transformation as governments around the world are now utilizing ICTs to improve efficiency and provide better information and services thus bringing out a phenomenon known as Electronic government (e-government). E-Government can be defined as the use of information and communication technologies (ICT) to deliver information from government and to provide online services and to interact and transact with citizens, businesses, and governments (Burn and Robins, 2003). Digital channels such as websites, mobile-based services, and public access points including databases, networking, discussion support, multimedia, automation, tracking and tracing and personal identification technologies are all included in E-government. The maturity of e-government has now extended to the realms of democracy where ICT tools have now been employed to enhance citizen participation. The field of citizen participation that has been affected by the revolution wave which has ICT as its cause is what is known as Electronic participation (e-participation) (Peristeras, 2009).

According to Macintosh and Whyte, (2008), the use of digital technologies to encourage and support "topdown" engagement and foster "ground-up" efforts to empower citizens to gain their support is referred to as eparticipation. E-Participation initiatives has served different objectives which includes provision of citizen's information, generation of support among citizens, utilization of citizens' views and opinions in decision making and asking for citizens' needs. A lot of ICT tools have been adopted in these initiatives and these are e-mails, online surveys, online discussion forums, group support systems and online chat. Even though e-participation is a young concept, its importance such as connecting citizens to businesses, other citizens and the government, increasing their participation in the making of decisions and delivery of services for an inclusive community and giving chances for civic engagement are very much appreciated. (Macintosh, 2006).

OECD (2002) in their quest for practicability of improved interaction through e-participation have identified three practical ways through which these interactions could be administered and these are information which is a one-way relationship in which the state circulates data on the making of policies and help the public get information. Consultation is a two-way relationship in which the state request for and takes citizens' feedback on policy-making and engaging citizens in decision-making and policy-making through active participation. E-participation's main purpose is to help raise natives' skills to participate in digital governance, including participating in the making of policy and political process and the transformation of digital government information and services.

Africa as a continent also has almost all their countries practicing democracy as their system of government 
thus, making citizen e-participation in policy and decision making process as a key part of its principles in its governance. According to Keane (2009), the development of representative democracy has been in existence for the past six decades with a gradual increase in public involvement in the policy-making and political processes. EParticipation is currently dominant among the debates of development theorists and information system researchers especially in Africa (Ghosh, 2014). In spite of the potentials of ICTs in improving the levels of citizens' engagement and facilitating decision making, there are still cases where such opportunities offered by ICTs are not being exploited. United Nations Development Programme (UNDP) Report on E-governance and participation in 2009 reveals that almost all African governments have the presence of website yet these developing countries experience difficulties in various degrees in getting access to new and modern technologies. This has resulted in developing countries not gaining as much as industrialized countries are gaining from the potential offered by these and therefore leaves these countries lagging behind.

Ghana being a peaceful country in West Africa and is seen as an epitome of democracy in developing countries in Africa since 1992. Engaging Citizens at the grass root level in decision making has been part of the country's administrative process and this is normally done through voting, discussions on various media platforms and meetings with leaders who have been chosen by the people as their representative in government. The government of Ghana devised e-government implementation strategy which also has e-participation included in May 2005 with the aim of providing an approach to initiating, implementing and sustaining efficient, economic and effective governance. (Isaac, 2016). Even though E-Government Interoperability Framework (E-GIF) policy document has revealed that Ghana's ICT environment is ready and one of Africa's Greenfield especially in egovernment initiatives and systems management and has a favourable condition available for e-participation yet participation in policy-making through information technologies is still low. This has become a major concern for government and major stakeholders on how to improve e-participation and increase citizen's interest and patronage in the perspective of policy making in Ghana. The questions addressed by this research are:

1) What are the reasons for low E-participation in policy making of local government in Ghana?

2) How can E-participation in policy making of local government be improved in Ghana?

\subsection{Methodology}

The study used explanatory research design, which focuses on why questions and logically relate those meaningmaking practices even though presenting how those practices align to produce visible results. It is essentially a kind of exploration design which emphases on explaining the aspects of the study in a comprehensive way. Explanatory research refers to a research approach that is centered on the hypothesis that societal truth is not objective, but is somewhat molded by human familiarities and social settings and is thus best premeditated within its socio-historic milieu by merging the personal explanations of its countless members since explanatory investigators see social reality as being entrenched within and difficult to abstract from their collective surroundings. Giorgi, A and Giorgi, B (2003).

\subsubsection{Data and Data Collection}

The study employed a probabilistic sampling technique. Under the probabilistic sampling technique, the simple random method was employed to choose participants who lived under the KMA jurisdiction.

Data used for the research was first-hand information gathered from respondents and data collected from journals and published papers. Primary data are those gotten from the field by the researcher via the running of questionnaires. Primary data sources are those items that are original to the problem under study' and how appropriate the researcher designs his/her research questions and how he or she relates with the problem. The secondary data consists of information that has already been collected for another purpose but which is available for this study, through articles, journals, magazines, internet, published and unpublished thesis. Secondary data can be used in comparison and they can provide the basis for analyses

\subsection{Literature Review \\ 2.1 E-Participation}

According to the UN, participation is a collective sustained action aimed at arriving at certain goals, objectives and agreement in order to stimulate development (UN, 2008). Organizations and social movements collectively use participation through organized effort to influence resources and regulate various institutions decisions in a given organization. According to (Macintosh \& Whyte 2008) e-participation is the use of any ICT equipment or gadget to enhance, facilitate, and encourage citizens to partake in politics and policies by enabling them to connect to and interact with elected officials and other citizens. Other researchers like (Sæbø, Rose \& Flak, 2008) defined e-participation as extending and transforming participation in a democratic society and through review processes facilitated by information and communication technologies (ICTs) primarily the internet. United Nations Department of Economics and Social Affairs has also indicated that E-participation is the process whereby citizens are engaged through ICTs in the making of policies, designing of service and its delivery for an inclusive and deliberative governance (UN, 2008). Medeglia, (2007) elaborated that, e-participation's adoption in governance is 
to enhance citizen and government relationship and interactions in an emerging technologically mediated innovation in "government to citizen" (G2C) relationships in the new e-democracy era.

\subsection{E-participation in Ghana}

The ripple effect of e-participation is a clear manifestation of its contribution to creating job opportunities that will stimulate business development. According to UNESCO (2007) one major benefit of e-participation in Africa is capacity building. Governments can also use this platform to collect and store and access it apart from reducing the process of data collection and analysis. In Ghana, the use of communication networks and the internet facilities will facilitate e-participation at all levels. According to the National Communications Authority, (2017) report, the number of mobile data subscribers in July was $22,103,467$ with $77.58 \%$ as its rate of penetration. Ghana can also boast of fourth generation $(4 \mathrm{G})$ internet network.

\subsection{Reasons for Low E Participation in Ghana}

\subsubsection{Trust}

Mayer, Davis \&Schoorman (1995) have defined trust as the readiness of a party to be vulnerable to the actions of another party based on the expectation that the other will perform a particular action important to the trustor, irrespective of the ability to monitor or control that other party". In the area of e-participation, this aspect can be seen as the willingness of citizens to engage in an e-participation process initiated by the government based on citizens' beliefs about the reliability and capability of the government. Trust has been revealed by numerous researchers to be an imperative element in the reception of e-government services where a high level of trust will definitely and meaningfully impact a user's intention to use a website (Papadoloulou, Nikoladou \& Martakos 2010). According to Hussein et al. 2010[54], there is evidence concerning citizens trust in the e-government process mainly during the previous encounters, and it is related to two factors which are citizens trust in government and citizens trust in the use of the internet. These two backgrounds of citizens' trust are used to measure citizens trust flexibility in government.

According to Bélanger \& Carter (2008), Citizens' trust in government can be defined as individual perceptions on the integrity and the capability of the government to provide service and is always base on the individual formal experience with the government. Citizen confidence in the government is the ability of the government to make service online always available and reliable. This is very important for building individuals trust in the eparticipation process taking into consideration that, trust and beliefs of citizens are dependent on expectations that the service provider provide. Kweit and Kweit (2007) argued that participation in government improved public service delivery and increased the trust of citizens in government.

\subsubsection{Gender Inequality and Culture}

Few studies in the area of e-government have conducted a research on the impact of the national cultural practice on e-government adoption as indicated by (Zhang et al. 2009). These scholars assumed that cultural dimensions in terms of collectivism, high power distance, low uncertainty avoidance, short term orientation, and femininity indirectly affect citizens' intention to use e-government services. Though, among these assumptions, high power distance and low uncertainty avoidance have repeatedly emerged as having a negative effect on the predictors of citizens or user's intentions thus, affecting the use of e-government services.

According to Leidner \& Kayworth (2006), the importance of high power distance and low uncertainty avoidance extents has been studied as factors that lead to the successful adoption of a new technology. In this research, the two cultural dimensions will be used; uncertainty avoidance according to (Hofstede, Hofstede \&Minkov1991) is the level to which individuals are endangered by uncertain situations. Citizens from high uncertainty avoidance societies will tend to cope with anxiety linked to uncertain circumstances by reducing the level of uncertainty such as avoiding uncertain circumstance totally. The e-participation is an emerging service in governance and for example, countries like Saudi Arabia, Nigeria, Ghana being a high uncertainty avoidance nation, apparently, and their citizens may tend to maintain the status quo of taking part in government policymaking process rather than the using the emerging e-participation service. It could, therefore, be argued that these countries being a society with high uncertainty avoidance culture would have a negative attitude towards using eparticipation. Similarly, the high uncertainty avoidance culture can also be anticipated to have an adverse impact on the citizen's trust feelings towards e-participation having in mind, societies of strong uncertainty avoidance cultures tend to see new situations as riskier and hence are more likely to avoid it.

\subsubsection{Low Literacy in Information Technology}

In the use of e-participation service, the level of citizen's information technology knowledge, skills, and abilities on the use of internet and the social media are considered as factors that will affect the use of e-participation in the policy-making process. Evidence has indicated that citizens who lack the knowledge and skills of IT are not motivated to let their views and opinions known through internet service. Scholars and researchers like, (Krishan et al., 2013), UN-Report, (2010) have identified three factors that can affect e-participation in a country; these factors are "information structure, governance, and human capital". 
Human capital according to Coff, (2002) refers to the knowledge, skills, abilities embodied in individuals residing in a country which enable them to participate in governance and its decision-making process. It can also be defined as, how literate and educated individuals are in terms of information technology. Schultz (1961) emphasized that the level of individual knowledge and skills in information technology play a critical role in the development of nations. Schultz (1961) further argued that human capital is a determinant factor that distinguishes between individuals and countries in terms of e-participation. Singh et al. (2007), believed that ICT infrastructure, governance, human capital, in the context of organizations facilitate the success and demands of e-government service in a country. Reports from (Krishan et al., 201; UN-Report, 2010) indicate that the individual level of literacy in information communication technology is closely linked with their level of e-participation, ability to share information online, e-consultations and online decision-making. The ICT infrastructures and the governance structure of a country determine the level of e-participation and on the other hand, a high level of human capital will influence the demands for e-participation.

Mayer, Davis \&Schoorman (1995) have defined trust as the readiness of a party to be vulnerable to the actions of another party based on the expectation that the other will perform a particular action important to the trustor, irrespective of the ability to monitor or control that other party". In the area of e-participation, this aspect can be seen as the willingness of citizens to engage in an e-participation process initiated by the government based on citizens' beliefs about the reliability and capability of the government. Trust has been revealed by numerous researchers to be an imperative element in the reception of e-government services where a high level of trust will definitely and meaningfully impact a user's intention to use a website (Papadoloulou, Nikoladou \& Martakos 2010). According to Hussein et al. 2010[54], there is evidence concerning citizens trust in the e-government process mainly during the previous encounters, and it is related to two factors which are citizens trust in government and citizens trust in the use of the internet. These two backgrounds of citizens' trust are used to measure citizens trust flexibility in government.

According to Bélanger \& Carter (2008), Citizens' trust in government can be defined as individual perceptions on the integrity and the capability of the government to provide service and is always base on the individual formal experience with the government. Citizen confidence in the government is the ability of the government to make service online always available and reliable. This is very important for building individuals trust in the eparticipation process taking into consideration that, trust and beliefs of citizens are dependent on expectations that the service provider provide. Kweit and Kweit (2007) argued that participation in government improved public service delivery and increased the trust of citizens in government.

\subsection{Data analysis and discussion \\ 3.1 Model Specification}

This study employed the ordinary least squares multiple regression econometric model in estimating the study. As a justification for the model, Maddala identified that the ordinary least square is more robust against specification error than many of the simultaneous equation methods of estimation and also states that productions from equations by ordinary least square are often favorably preferred compared with those obtained from the use of equations estimated by the simultaneous equation method. This study adopts the OLS because of several reasons, thus; the mechanics of the OLS are simple to understand, the OLS is an essential component of most econometric techniques and the computational procedure of the OLS is fairly simple as compared with other econometric techniques.

Among other reasons, the simplicity of the OLS computational procedure makes it a choice approach to be used for this study. The method of the OLS is used popularly not only because it is easy to use but also because it has some strong theoretical properties, which are summarized in the well-known Gauss-Markov theorem. The multiple regression model is specified as follows:

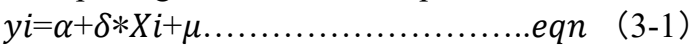

Where; $y$ represents the dependent variable and determined by two major components which includes the nonrandom component $X$ which represents the explanatory variables and $\delta$ as the coefficient of the explanatory variables and alpha being the constant time.

$E P=\alpha+\delta 1 T t F+\delta 2 S F+\delta 3 T F+\mu$

$$
\text { eqn (3-1) for } \delta i>0
$$

Where EP represents the electronic participation which in this study is the dependent variable; $\alpha$ signifies the intercept or the constant term, $T t F$ symbolizes the trust factors that influence the electronic participation, $S F$ also characterizes the social factors that influence the electronic participation and $T c h F$ is the technical factors. $\delta i$ epitomizes the coefficients of the independent variables, and $\mu$ explains the error term of the model. Again, to enable the interpretation of the partial elasticities, which addresses the degree of responsiveness of the dependent variable to the respective economic independent variable, it is essential to introduce log into the model. This transformed the model into $\ln E P=\ln \alpha+\delta 1 \ln T t F+\delta 2 \ln S F+\delta 3 \ln T \operatorname{ch} F+\ln \mu$ $e q n$ 


\subsection{Analysis of Variance (ANOVA)}

The study used F-statistic to determine the relationship between dependent variable and independent variables. Generally, the F-statistic is used to determine whether the difference among various sample means is statistically significant or it is just a case of sampling variations. The null hypothesis is rejected if the estimated F-statistic exceeds the critical value of the F-distribution. The calculation of F-statistic is summarized and presented in Table 3.2 .

Table 1 Analysis of Variance (ANOVA)

\begin{tabular}{|c|c|c|c|c|}
\hline $\begin{array}{c}\text { Source of } \\
\text { variation }\end{array}$ & Sum of squares & Degree of freedom & Mean square & \multirow{2}{*}{ F-statistic } \\
\cline { 1 - 3 } $\begin{array}{c}\text { Between } \\
\text { samples }\end{array}$ & $S S B$ & $k-1$ & $M S B$ & \multirow{2}{*}{$F=\frac{M S B}{M S W}$} \\
\hline Within samples & $S S W$ & $n-k$ & $M S W$ & \\
\hline Total & $S S T=S S B+S S W$ & $n-1$ & & \\
\hline
\end{tabular}

Where $S S B$ is the sum of squares for variance between samples, $S S W$ shows the sum of squares for variance within samples, $S S T$ represents the sum of squares for total variance, $k$ represents number of samples, $n$ denotes the total number of items in all the samples, $(k-1)$ indicates the degree of freedom between samples, $(n-k)$ shows the degree of freedom within samples, $M S B$ connotes the mean square between samples, and $M S W$ indicates the mean square within samples.

Table 2 Demographic of Respondents

\begin{tabular}{|c|c|c|c|}
\hline & & Frequency & $\%$ \\
\hline \multirow{3}{*}{ Gender } & Male & 105 & 47.9 \\
\hline & Female & 114 & 52.1 \\
\hline & Total & 219 & 100.0 \\
\hline \multirow{5}{*}{ Age of Respondents } & Below 18 yrs & 11 & 5.0 \\
\hline & $18-34$ & 122 & 55.7 \\
\hline & $35-54$ & 67 & 30.6 \\
\hline & Above 55 & 19 & 25.1 \\
\hline & Total & 219 & 100.0 \\
\hline \multirow{5}{*}{ Education of Respondents } & Senior High School & 61 & 27.9 \\
\hline & Undergraduate & 90 & 41.1 \\
\hline & Master & 48 & 21.9 \\
\hline & Doctorate & 20 & 9.1 \\
\hline & Total & 219 & 100.0 \\
\hline
\end{tabular}

\subsection{Sex Distribution of Respondents}

The statistics shown in table 1 below indicates that $(47.9 \%)$ of respondents were males as against $(52.1 \%)$ of females. These percentages were gotten from 105 males and 114 females respectively. This would make the study devoid of gender inequality. Therefore, sex of respondent was useful as the researcher was able to know the gender balance so as to make constructive analysis devoid of gender disparity.

\subsection{Age Distribution of Respondents}

The table 1 below illustrates the data collected from the field and the respondents who participated in the survey and responded to issues raised had majority of them thus $122(55.3 \%)$ between the age range of 18-34 years, this was followed closely by those who were between $35-54$ years forming 67 (30.6\%). Also, $19(25.1 \%)$ were above 55 years and lastly $11(5 \%)$ were below 18 years. The age of respondents helped the researcher to differentiate between the different categories of respondents. Moreover, the majority of the respondents dominated by 18-34 years signifies that there quite matured people and therefore decision-making is done effectively. That is if we believe in the school of thought that, old age corresponds with maturity.

\subsection{Education of Respondents}

Yet another significant feature of the respondents the study explored was their level of education. Significantly, majority $90(41.1 \%)$ respondents emphasized that they have first-degree certificate. closely followed by this revelation is $61(27.9 \%)$ who identified that they have obtain high school certificate. Participants who indicated that they have second-degree certificate (masters) followed by $48(21.9 \%)$ and $20(9.1 \%)$ indicated that they had doctorate degree. Convincingly, for majority of the respondents to indicate that they had first-degree education implies that most of the respondents are well educated. 


\subsection{Reasons for Low E-participation in policy making of Local Government}

The ethical reasons regarding low E-participation were explored in-depth and the statistics on the table below present the findings of the respondents' remarks. As to whether the respondents have trust and confidence in the government that their views and inputs are considered in policy making, $133(60.8 \%)$ averred that they do not in any means trust and confidence in the government that their views and inputs are considered in policy making. In contradiction, $86(39.2 \%)$ were divergent in opinion to that effect while none of the respondents were unconcerned about the issue. Considering the systems and channels for e-participation in local government are strong and cannot be easily manipulated, majority of $110(50.2 \%)$ respondents intimated that the systems and channels for eparticipation in local government are strong and can be easily manipulated. However, an insignificant $55(25.1 \%)$ respondents disproved the assertion while $54(24.7 \%)$ were uncertain in their response.

Equality before the law has been a major debate in most countries. If institution could engage equal gender, it could breed higher efficiency especially in the information era where women dominate the market. This study sought to identify the extent to which women are intricate in e-participation activities in local government during policy making. Surprisingly, $135(61.5 \%)$ of the respondents affirmed their disagreement to the fact that, women are intricate in e-participation activities in local government during policy making. That notwithstanding, 45 $(20.6 \%)$ respondents averred their agreement to that effect while surprisingly, $39(17.8 \%)$ half way to respondents who agreed to the assertion were indecisive to this assertion. It was however realized that the availability of technology and e-participation channels has resulted in increased e-participation. This was statistically revealed by $123(56.2 \%)$ respondents. However, $38(17.3 \%)$ opposed that the availability of technology and e-participation channels has resulted in increased e-participation while insignificantly only $58(26.5 \%)$ was neutral to the response on this assertion.

Once again, the study identified that low literacy in technology makes it difficult to participate in online discussions during policy making. Emphatically, $183(83.6 \%)$ intimated that indeed the low literacy in technology makes it difficult to participate in online discussions during policy making. Inconsistently, $21(9.6 \%)$ were divergent about this assertion while $15(6.8 \%)$ were uncertain.

Table 3 Reasons for Low e-participation in policy making of Local government

\begin{tabular}{|c|c|c|c|c|c|}
\hline 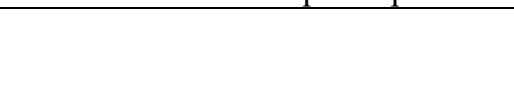 & $\begin{array}{l}\text { Strongly } \\
\text { Disagree }\end{array}$ & Disagree & Uncertain & Agree & $\begin{array}{c}\text { Strongly } \\
\text { Agree }\end{array}$ \\
\hline & N (\%) & $\mathbf{N}(\%)$ & N (\%) & $\begin{array}{c}\mathrm{N} \\
(\%)\end{array}$ & $\mathbf{N}(\%)$ \\
\hline $\begin{array}{l}\text { - I have trust and confidence in } \\
\text { the gov't. that my views and } \\
\text { inputs are considered in policy } \\
\text { making }\end{array}$ & $\begin{array}{c}79 \\
(36.1)\end{array}$ & $\begin{array}{c}54 \\
(24.7)\end{array}$ & $\begin{array}{c}0 \\
(0.0)\end{array}$ & $\begin{array}{c}33 \\
(15.1)\end{array}$ & $\begin{array}{c}53 \\
(24.1)\end{array}$ \\
\hline $\begin{array}{l}\text { The systems and channels for } \\
\text { e-participation in local gov't } \\
\text { are strong and can't be easily } \\
\text { manipulated }\end{array}$ & $\begin{array}{c}58 \\
(26.5)\end{array}$ & $\begin{array}{c}52 \\
(23.7)\end{array}$ & $\begin{array}{c}54 \\
(24.7)\end{array}$ & $\begin{array}{c}35 \\
(16.0)\end{array}$ & $\begin{array}{c}20 \\
(9.1)\end{array}$ \\
\hline $\begin{array}{l}\text { Women are more involved in } \\
\text { e-participation activities in } \\
\text { local gov't during policy } \\
\text { making }\end{array}$ & $\begin{array}{c}82 \\
(37.4)\end{array}$ & $\begin{array}{c}53 \\
(24.1)\end{array}$ & $\begin{array}{c}39 \\
(17.8)\end{array}$ & $\begin{array}{c}24 \\
(11.0)\end{array}$ & $\begin{array}{c}21 \\
(9.6)\end{array}$ \\
\hline $\begin{array}{l}\text { The availability of technology } \\
\text { and e-participation channels } \\
\text { has resulted in increased e- } \\
\text { participation }\end{array}$ & $\begin{array}{c}15 \\
(6.8)\end{array}$ & $\begin{array}{c}23 \\
(10.5)\end{array}$ & $\begin{array}{c}58 \\
(26.5)\end{array}$ & $\begin{array}{c}97 \\
(44.3)\end{array}$ & $\begin{array}{c}26 \\
(11.9)\end{array}$ \\
\hline $\begin{array}{l}\text { Low literacy in technology } \\
\text { makes it difficult to } \\
\text { participate in online } \\
\text { discussions during policy } \\
\text { making }\end{array}$ & $\begin{array}{c}14 \\
(6.4)\end{array}$ & $\begin{array}{c}7 \\
(3.2)\end{array}$ & $\begin{array}{c}15 \\
(6.8)\end{array}$ & $\begin{array}{c}63 \\
(28.8)\end{array}$ & $\begin{array}{c}120 \\
(54.8)\end{array}$ \\
\hline
\end{tabular}

Source: Field Data, 2019

The researcher further used multiple regression to investigate the reasons that influence E-participation in policy making of local government in Ghana by grouping each statement relating to reasons of low E-participation under their respective factors as displayed in the conceptual framework in the previous chapter. In Table 4.4 below, $T t F$ denotes trust factors, $S F$ represents social factors and $T c h F$ signifies technical factors. The study employed the ordinary least squares multiple regression econometric model in estimating the impact.

From the results of the multiple linear regression displayed in Table 4.4, the coefficient of determination $\mathrm{R}^{2}$ 
(0.967) indicates that $96.7 \%$ of the variations in the dependent variable (E-participation) is explained jointly by the independent variables (trust factors; social factors; and technical factors). The study found that trust factors have a negative influence on electronic participation in policy making of local government in Ghana and not significant at any level of significance. This result is not surprising as it is evident that every single individual has trust issues and taking a critical look at the descriptive analysis, it is evidence that, most of the respondents do not trust the system as they constitute $36.1 \%$ of the total sample used in the study.

The study further, portrayed that, social factors such as gender inequalities have a positive impact on Eparticipation in policy making of local government in Ghana. This result was found at $10 \%$ level of significant. With its coefficient of 1.61410 , a unit improvement in with respect to gender inequality within the local government policy making in Ghana will result in $0.11 \%$ development in the E-participation holding all other variables constant while the inverse is true as well. This implies that social factors are significant determinants of E-participation in policy making of local government in Ghana. Finally, the study asserted that technical factors consisting of technological infrastructure and information technology literacy has a positive impact on Eparticipation in policy making of local government in Ghana. This result was found at 10\% level of significant. With its coefficient of 1.29139 , a $10 \%$ improvement in technological infrastructure and information technology literacy will result in $0.25 \%$ enhancement in the E-participation in policy making of local government in Ghana. This result indicates that there is sufficient evident to suggest that the coefficient of technical factors is significant in predicting the E-participation in policy making of local government in Ghana all things being equal, the vice versa is true.

The general multiple regression model for this study will be

$$
L E_{P}=\alpha+\delta_{1} T t F+\delta_{2} S F+\delta_{3} T c h F+\mu
$$

Table 4 One Method Regression Results for factors that imped Low E-participation

\begin{tabular}{|c|c|c|c|c|c|c|c|c|}
\hline \multirow{2}{*}{\multicolumn{2}{|c|}{ Model }} & \multicolumn{2}{|c|}{$\begin{array}{l}\text { Unstandardized } \\
\text { Coefficients }\end{array}$} & \multirow{2}{*}{$\begin{array}{c}\begin{array}{c}\text { Standardized } \\
\text { Coefficients }\end{array} \\
\text { Beta }\end{array}$} & \multirow[t]{2}{*}{$\mathrm{T}$} & \multirow[t]{2}{*}{ Sig. } & \multicolumn{2}{|c|}{$\begin{array}{c}\text { Collinearity } \\
\text { Statistics }\end{array}$} \\
\hline & & $\mathrm{B}$ & $\begin{array}{l}\text { Std. } \\
\text { Error }\end{array}$ & & & & Tolerance & VIF \\
\hline \multirow[t]{8}{*}{1} & (Constant) & -4.929 & .433 & & $\begin{array}{c}- \\
11.389\end{array}$ & .000 & & \\
\hline & $\mathrm{TF}$ & .011 & .197 & .002 & .057 & .955 & .125 & 7.986 \\
\hline & SF & 1.288 & .085 & .718 & 15.179 & .000 & .059 & 16.982 \\
\hline & TchF & .897 & .187 & .272 & 4.807 & .000 & .041 & 24.346 \\
\hline & \multicolumn{2}{|l|}{$\mathrm{R}$} & & $.986^{\mathrm{a}}$ & & & & \\
\hline & \multicolumn{2}{|c|}{ R Square } & & .972 & & & & \\
\hline & \multicolumn{2}{|c|}{ Adjusted R Square } & & .971 & & & & \\
\hline & \multicolumn{2}{|c|}{$\begin{array}{l}\text { Std. Error of the } \\
\text { Estimate }\end{array}$} & & 1.00972 & & & & \\
\hline
\end{tabular}

Note: Dependent Variable: LEP ***1\% significant level

Source: Researcher's survey, 2019

\subsection{Analysis of Variance (ANOVA)}

This analysis was done to determine the fitness of the regression model using the F-Statistic, and the results for the analysis of variance are presented in Table 5.

Table 5 Results for the Analysis of Variance

\begin{tabular}{|l|l|l|l|}
\hline & Sum of squares & Degree of freedom & Mean square \\
\hline Regression & 11709.2 & 3 & 3903.07 \\
\hline Residual & 399.365 & 214 & 1.86619 \\
\hline Total & 12108.6 & 217 & 55.7999 \\
\hline $\mathrm{R}^{\wedge} 2=11709.2 / 12108.6=0.967018$ & \\
\hline $\mathrm{F}(3,214)=3903.07 / 1.86619=2091.46[\mathrm{p}$-value 3.29e-158] \\
\hline
\end{tabular}

Source: Researcher's survey, 2019

Hypothesis of testing the model fitness

$H_{0}$ : The model does not fit well the dataset.

$H_{1}$ : The model fit well the dataset.

Considering the p-value (0.000) of the F-statistic (2091.46), the multiple regression was found to be significant at $5 \%$. This implies that there is enough evidence to reject the null hypothesis that model is not well fit for the dataset; hence suggesting that the model best fit the dataset used in this study. This confirms that over ally the multiple regression model is statistically significant, in that it is a suitable prediction model for explaining how 
the factors contribute to low e-participation in local government of Ghana.

\subsection{Suggestions as to how to improve E-participation in Local Government}

It is the goal of every country to promote its economy. African countries especially Ghana in recent times is putting in place measures that can intricate her citizens into the digital world. Government has recently done this through the implementation of the GPS. The study explored the activities that can help improve E-participation in local government in Ghana. Indisputably, the table 4.6 below gives the statistical findings of the responses of the study. An overwhelming majority 160 (73\%) of the respondents indicated that their literacy in technology will influence e-participation. Strangely, $25(11.4 \%)$ also averred their disagreement to the assertion that literacy in technology will influence e-participation whereas, $28(12.8 \%)$ were not certain. The study further asked that should in case they have better internet infrastructure will they patronize E-participation, impressively, 178 representing $81.3 \%$ of the respondents indicated that they will gladly patronize E-participation should there be a better internet infrastructure. This implies that there is no reliable internet infrastructure within the operations of the local government in Ghana. The study again sought to find out if trust and confidence in the government will influence the usage of e-participation tools. Interestingly, majority $176(80.3 \%)$ of the respondents affirmed to the fact that trust and confidence in the government will influence the usage of e-participation tools. Again, majority of 190 $(86 \%)$ indicated that their participation will be high if their views and options are utilized by the government in policy making. This whopping affirmation is a clear indication that should all hands be welcome to contribute to decision making, there will be a better governance to promote the country. It is therefore required of the government and its stakeholders should act immediately to intricate its citizens in decision making. Table 6 How to improve e-participation in Ghana

\begin{tabular}{|c|c|c|c|c|c|}
\hline & $\begin{array}{l}\text { Strongly } \\
\text { Disagree }\end{array}$ & Disagree & Uncertain & Agree & $\begin{array}{c}\text { Strongly } \\
\text { Agree }\end{array}$ \\
\hline & $\mathrm{N}(\%)$ & N (\%) & N (\%) & $\begin{array}{l}\mathrm{N} \\
(\%)\end{array}$ & N (\%) \\
\hline $\begin{array}{l}\text { - My literacy in technology will } \\
\text { influence e-participation }\end{array}$ & $\begin{array}{c}18 \\
(8.2)\end{array}$ & $\begin{array}{c}7 \\
(3.2)\end{array}$ & $\begin{array}{c}28 \\
(12.8)\end{array}$ & $\begin{array}{c}87 \\
(39.7)\end{array}$ & $\begin{array}{c}73 \\
(33.3)\end{array}$ \\
\hline $\begin{array}{l}\text { - I will patronize e-participation if } \\
\text { I have better internet } \\
\text { infrastructure }\end{array}$ & $\begin{array}{c}5 \\
(2.3)\end{array}$ & $\begin{array}{c}11 \\
(5.0)\end{array}$ & $\begin{array}{c}25 \\
(11.4)\end{array}$ & $\begin{array}{c}88 \\
(40.2)\end{array}$ & $\begin{array}{c}90 \\
(41.1)\end{array}$ \\
\hline $\begin{array}{l}\text { - My trust and confidence in the } \\
\text { government will influence my } \\
\text { usage of e-participation tools }\end{array}$ & $\begin{array}{c}1 \\
(0.5)\end{array}$ & $\begin{array}{c}17 \\
(7.8)\end{array}$ & $\begin{array}{c}25 \\
(11.4)\end{array}$ & $\begin{array}{c}73 \\
(33.3)\end{array}$ & $\begin{array}{c}103 \\
(47.0)\end{array}$ \\
\hline $\begin{array}{l}\text { - My participation will be high if } \\
\text { my views and options are } \\
\text { utilized by the government in } \\
\text { policy making }\end{array}$ & $\begin{array}{c}4 \\
(1.8)\end{array}$ & $\begin{array}{c}7 \\
(3.2)\end{array}$ & $\begin{array}{c}18 \\
(8.2)\end{array}$ & $\begin{array}{c}63 \\
(28.8)\end{array}$ & $\begin{array}{c}127 \\
(58.0)\end{array}$ \\
\hline
\end{tabular}

Source: Field Data, 2019

\subsection{Conclusions}

The study concluded that the reasons for low E-participation in local government of Ghana is that, there is no trust and confidence in the government that citizen's views and inputs are considered in policy making, the systems and channels for e-participation in local government are not strong and can be easily manipulated, there is also inequality thus to say women are not intricated in e-participation activities in local government during policy making. In order to improve the E-participation in local government of Ghana, the study concluded that there is the need for a better internet infrastructure and government must perform to expectation in order to earn the trust and confidence of the citizens which will enhance the e-participation. There is also the need to involve all stakeholders in E-participation by the government in policy making.

Finally, the study concluded that trust factors have a negative influence on electronic participation in policy making of local government in Ghana and is not statistically significant whereas social factors such as culture and gender inequalities have a positive impact E-participation in policy making of local government in Ghana technical factors consisting of technological infrastructure and information technology literacy has a positive impact on Eparticipation in policy making of local government in Ghana. The study finally, concluded that all variables employed (trust factors, social factors, technical factors and E-participation) in the study have strong correlation coefficient and are all significant.

6.0 Recommendations based on the Research Findings

The study as part of its discovery identified education, better internet infrastructure and involvement in decision 
making as one major factor that could enhance the E-participation among the citizens at the local government in Ghana. It is therefore recommended that the authorities at the various local governments in Ghana must put in place a better internet system and then follow suit with an intensive workshop on how to utilize the facility to its maximum. The government should also create a portal through which comments and suggestions regarding policies can be contributed to by the local government officials and all other stakeholders.

The study as part of its findings identified a significant positive relationship between trust factors, social factors technical factors and E-participation. The study therefore recommends to the entire local government and government that the approach to enhance e-participation is to attach great importance to regional development. With evidence of positive impact of social and technical factors, the government should pay a critical attention to policies that will satisfy all and not just selective areas of the country as it is also evidence that there is the need for government to win the trust of the people.

\subsection{References}

J Burn and G. Robins (2003). Moving towards E-government: A Case Study of Organizational Change Processes. Logistics Information Management, , 16(1):25-35

V. Peristeras, G. Mentzas, K. A. Tarabanis, et al (2009). Transforming E-Government and E-Participation through IT .IEEE Intelligent Systems, 24(5)

A. Macintosh and A. Whyte (2008). Towards an Evaluation Framework for E-Participation. Transforming Government: People, Process and Policy, 2(1):16-30

A. Macintosh (2006). E-Participation in Policy-Making: The Research and the Challenges. Exploiting the Knowledge Economy: Issues, Applications and Case Studies, 364-369

I. Peña-Lopez (2001). Citizens as Partners. OECD Handbook on Information, Consultation and Public Participation in Policy-Making.

J. Keane (2009). The Life and Death of Democracy. Simon and Schuster,

J. Ghosh (2014). Relevance and Use of ICT in Grassroots' Participation in Panchayats. Journal: Global Media Journal-Indian Edition,

I. K. Mensah (2015). Overview of E-government Adoption and Implementation in Ghana. World Academy of Science, Engineering and Technology, International Journal of Social, Behavioural, Educational, Economic, Business and Industrial Engineering, , 10(1):61

United Nations (2008). People Matter: Civic Engagement in Public Governance. World Public Sector Report, New York: UN-DESA,

Ø. Sæbø, J. Rose and L. S. Flak (2008,). The Shape of E-Participation: Characterizing an Emerging Research Area. Government Information Quarterly, 25(3):400-428

R. Medaglia (2007). Measuring the Diffusion of E-Participation: A Survey on Italian Local Government. Information Polity, , 12(4):265-280

UNESCO (2007). Curriculum Guide On E-Governance for African Government Institutions.

National Communications Authority. Telecom Data Subscription. Retrieved September 4, 2017, from https://nca.org.gh/industry-data-2/market-share-statistics-2/data-3/

R.C.Mayer, J.H. Davis, and F.D. Schoorman(1995). An Integrative Model of Organizational Trust. Academy of Management Review, , vol. 20, $709-34$

P. Papadoloulou, M. Nikoladou, and D. Martakos(2010). 'What is Trust in E-Government? A proposed Typology. Proceedings of the 43rd Hawaii International Conference on System Sciences, , 1-10

R. Hussein, N, Mohamed Ahlan, A.R. M Mahmud and U. Aditiawarman,( 2010 ), 'G2C Adoption of EGovernment in Malaysia Trust, Perceived Risk and Political Self-Efficacy. International Journal of Electronic Government Research, Vol. 6, No. 3, 57-72

F. Bélanger and L. Carter (2008,). Trust and Risk in E-Government Adoption. Journal of Strategic Information Systems, vol. 17, no. 2, 165-76

Kweit, G. Mary and W. Robert Kweit(2007). Participation, Perception of Participation, and Citizen Support. American Politics Research 35(3),: 407-425

A. Alzahrani(2011). Web-based E-Government Services Acceptance for G2C: A Structural Equation Modelling Approach. De Montfort University, Leicester,

Zhang Huiping, Wu Shuailei, Tang Zhiwei (2017). The study of the influence factors of different levels of network participation behaviour in the process of policy formulation. E-government, (1): 50-58

D.E. Leidner and T. Kayworth (2006,). 'Review: A Review of Culture in Information Systems Research: Toward a Theory of Information Technology Culture Conflict', MIS Quarterly,Vol. 30, No. 2, 357-99

G.Hofstede, G.J. Hofstede and M. Minkov (, 1991). Cultures and Organizations Software of the Mind, Vol 2, McGraw-Hill London

S. Krishnan, T. Teo, and J. Lim (2013). E-participation and E-Government Maturity. A Global Perspective in Grand Successes and Failure in IT. In Public and Private Sectors 2013 Proceedings of the IFIP WG8. 6 
International Working Conference on Transfer and Diffusion of IT in Bangalore, India. Beelin, Heidelberg: Springer, 420-435

UN-Report (2010). Leveraging E-Government at a Time of Financial and Economic Crisis.

R.Coff (2002). Human Capital, Shared Expertise and the Likelihood of Impasse in Corporate Acquisitions. Journal of Management , 28(1), 107-128

T. Schultz (1961). Investment in Human Capital. American Economic Review, 51 (1), 1-17

H.D.Singh, A. and D. Joseph (2007). Country-level Determinants of E-Government Maturity. Communications of the Association for Information Systems, 20(1) 632-648

A.Giorgi, and B Giorgi (2003). Phenomenology. In J A Smith (ed.) Qualitative Psychology: A Practical Guide to Research Methods London: Sage Publications, 